\title{
Phenelzine-Induced Myocardial Injury: a Case Report
}

\author{
Adeline Su-Yin Ngo • Raymond Y. Ho • Kent R. Olson
}

Published online: 21 July 2010

(C) American College of Medical Toxicology 2010

\begin{abstract}
Introduction Phenelzine is an irreversible monoamine oxidase inhibitor (MAOI). Hypertensive reactions after ingestion of tyramine-rich foods such as cheese are well known. However, a review of the available medical literature found no previous reports of myocardial infarction resulting from the ingestion of cheese by a patient taking a MAOI.

Case Report A 34-year-old female taking phenelzine for depression developed severe chest pain $1 \mathrm{~h}$ after eating cheese. She was hypertensive and the electrocardiography showed ischemic changes in the antero-lateral chest leads. The chest pain and elevated blood pressure were relieved with intravenous morphine and nitroprusside. The initial serum troponin I level was normal, but serial repeat levels showed a rising trend with a peak at $4.89 \mathrm{ug} / \mathrm{L}$ (reference range $<0.05 \mathrm{ug} / \mathrm{L}$ ) $6 \mathrm{~h}$ after the initial blood draw, suggestive of a non-ST elevation myocardial infarction. The patient subsequently developed hypotension $4 \mathrm{~h}$ after another therapeutic dose of phenelzine was served to the patient $4 \mathrm{~h}$ after her admission to the ED. This was corrected with at least $2 \mathrm{~L}$ of intravenous normal saline boluses. Subsequent EKGs and Sestamibi scan showed no evidence of cardiac ischemia. She was discharged home after a hospital stay of 3 days.
\end{abstract}

\footnotetext{
A. S.-Y. Ngo $(\bowtie)$

Department of Emergency Medicine,

Singapore General Hospital,

Outram Road,

Singapore 169608, Singapore

e-mail: angosy@gmail.com

R. Y. Ho $\cdot$ K. R. Olson

California Poison Control System,

San Francisco Division,

San Francisco, CA, USA
}

Discussion We believe this to be the first reported case of myocardial infarction resulting from ingestion of cheese in a patient taking a MAOI. It might be expected that hypertensive crisis could lead to a myocardial infarction, but a review of the medical literature found no such cases reported.

Keywords Nardil ${ }^{\circledR}$ - Monoamine oxidase inhibitor. Myocardial infarction

\section{Introduction}

Phenelzine is an irreversible monoamine oxidase inhibitor (MAOI) and a hydrazine [1]. Transient hypertensive crisis following ingestion of certain drugs (such as pseudoephedrine) or tyramine-rich foods (such as aged cheese, red wine, and fava beans) is a well-recognized complication of MAOI therapy [2]. The use of MAOI has been reduced markedly since the discovery of less toxic and more predictable tricyclic agents [1] and the selective serotonin reuptake inhibitors, serotonin-norepinephrine reuptake inhibitors, and other antidepressants, resulting in very few case reports of MAOI toxicity over the past 15 years. Complications resulting in an acute cardiac event could be anticipated. However, our review of the medical literature including medical toxicology textbooks found no previous reports of acute myocardial infarction resulting from MAOI-induced hypertensive crisis.

\section{Case Report}

A 34-year-old female with a history of depression had been maintained on phenelzine at a dose of $22.5 \mathrm{mg}$ at noon and $15 \mathrm{mg}$ at bedtime. She had no prior history of hypertension, 
Fig. 1 Electrocardiography on admission to emergency department

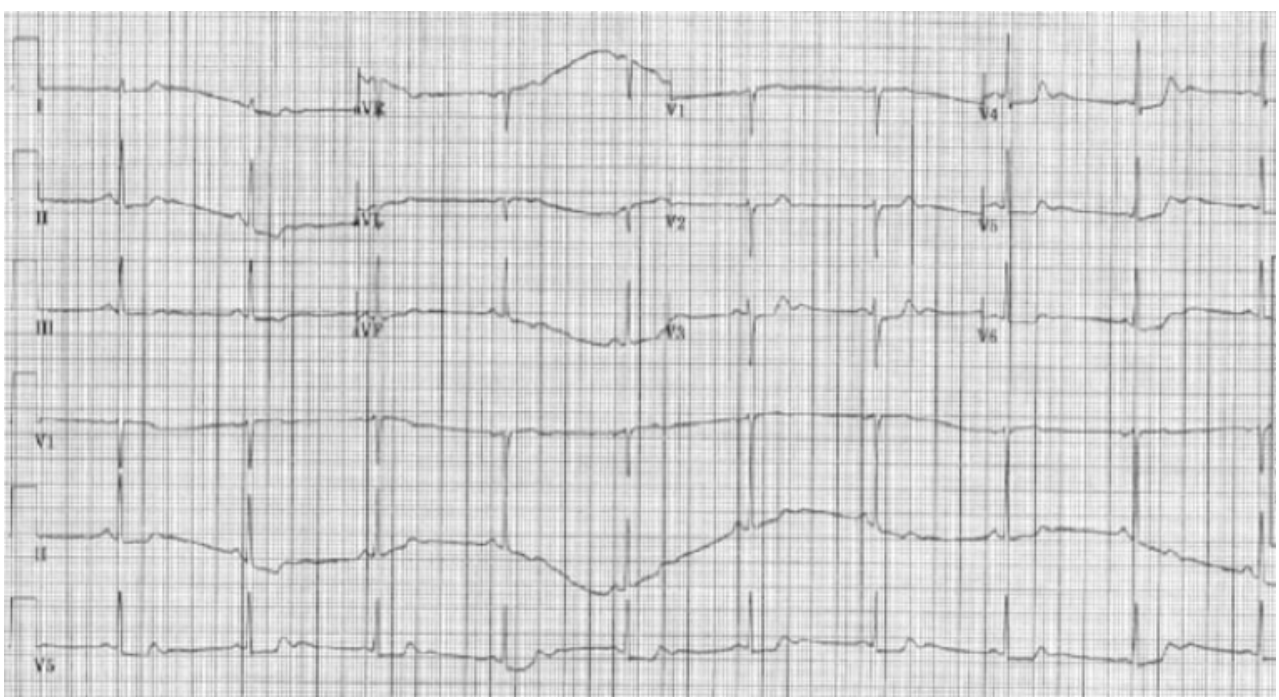

headache, chest pains, and other neurological or cardiac symptoms. She denied any intentional drug overdose or abuse. The patient ingested some cheese approximately $3 \mathrm{~h}$ after her last dose of phenelzine. The quantity and type of cheese ingested was unclear. Within 1 to $2 \mathrm{~h}$, she developed chest pain, breathlessness, and a severe headache.

In the emergency department, she was noted to be hyperventilating and severely anxious. She described her occipital headache to be $10 / 10$ in severity on the visual analog scale. She complained of a sensation of heaviness in her chest. Her initial blood pressure was 176/80 mmHg, pulse was 80 per minute and regular, respiratory rate was 22 per minute, and she was maintaining a saturation of $100 \%$ on room air. Her cardiac and neurological examination was essentially normal. A computerized tomography imaging of the head did not show any intracerebral bleed. However, the patient's electrocardiogram (EKG) showed
ST depression with horizontalization over the antero-lateral chest leads (Fig. 1). The initial troponin I level was normal at $0.02 \mathrm{ug} / \mathrm{L}$ (reference range $<0.05 \mathrm{ug} / \mathrm{L}$ ). Toxicology screen was negative for drugs of abuse.

Her chest discomfort improved after small boluses of intravenous morphine. A repeat EKG showed reversal of the ST depression after the morphine was administered (Fig. 2). She was managed as having unstable angina and was treated with aspirin. Intravenous nitroprusside was started to control the hypertension. The blood pressure was still elevated and reached a peak SBP of $200 \mathrm{mmHg}$. A repeat troponin level $6 \mathrm{~h}$ after the initial blood draw was $4.89 \mathrm{ug} / \mathrm{L}$. An EKG was done at this point and it did not show any evidence of ischemia (Fig. 3). The patient was served her therapeutic dose of phenelzine at this time. She then developed hypotension $(65 / 30 \mathrm{mmHg})$ despite tapering of the nitroprusside dose, This was then treated
Fig. 2 Electrocardiography of the patient after receiving morphine and nitroprusside

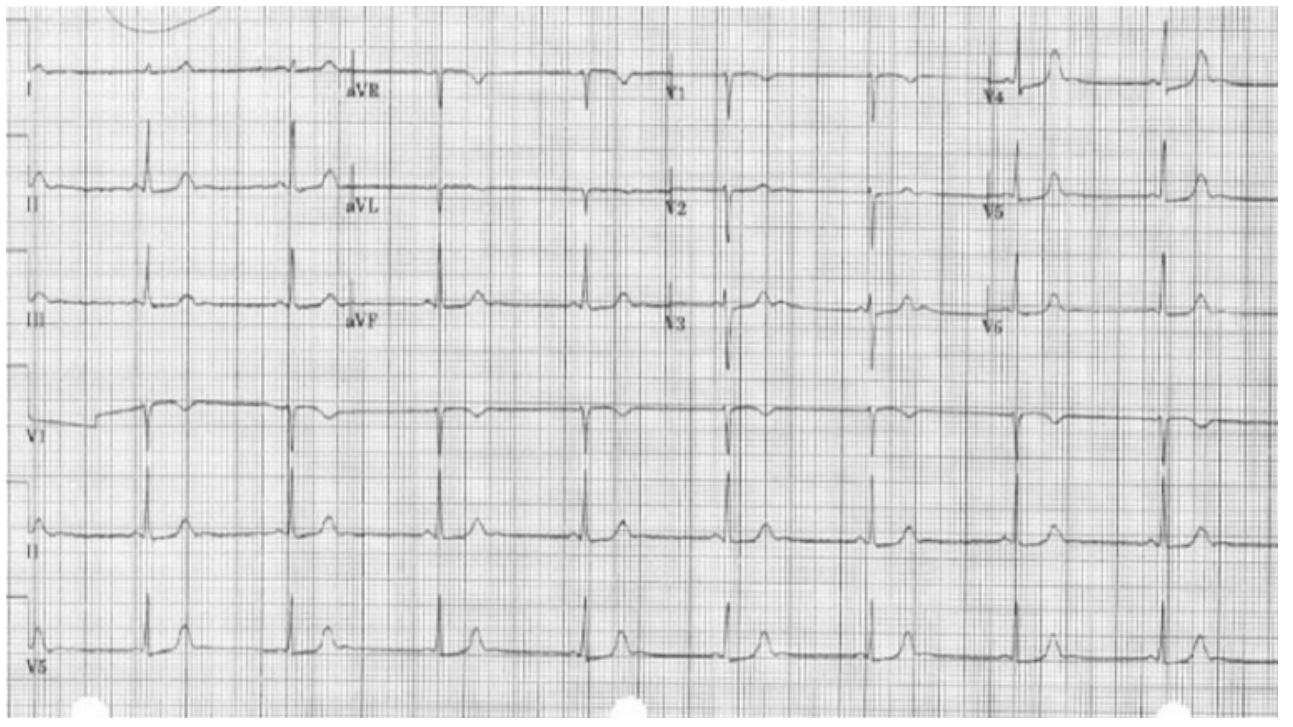


Fig. 3 Electrocardiography of the patient at time of peak troponin leak $6 \mathrm{~h}$ after admission

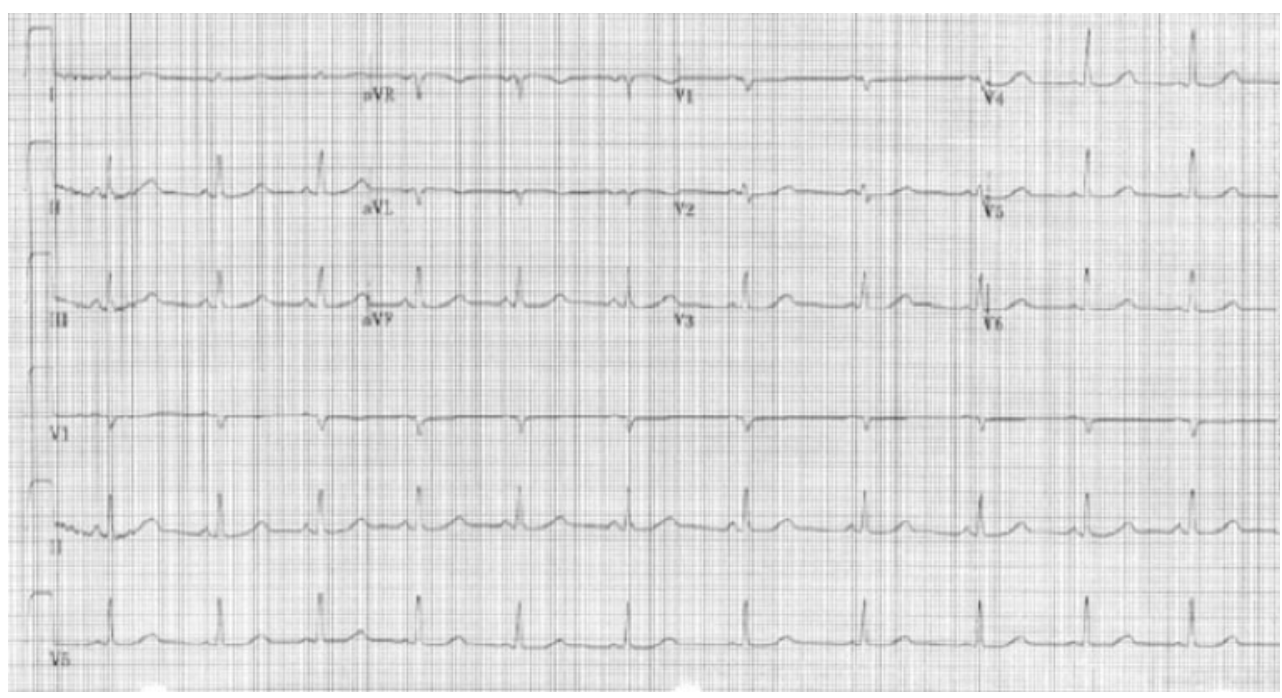

successfully with at least $2 \mathrm{~L}$ of intravenous fluid boluses. She was monitored in the intensive care unit. Although she complained of occasional episodes of dizziness, the headaches and chest discomfort had resolved. The third troponin level $9 \mathrm{~h}$ after admission was $1.89 \mathrm{ug} / \mathrm{L}$. Cardiac consultation was obtained and a Sestamibi scan was performed, which showed no evidence of coronary artery disease. She was discharged home after 3 days. Her blood pressure was $99 / 60 \mathrm{~mm} \mathrm{Hg}$ prior to discharge. The EKG done prior to discharge is shown in Fig. 4.

\section{Discussion}

We believe this to be the first reported case of myocardial infarction resulting from a MAOI-induced hypertensive crisis. MAOIs exert their effects by reducing the neuronal metabolism of sympathomimetic amines and 5-hydroxytryptophan.
This results in increased stores of releasable norepinephrine in post-ganglionic sympathetic neurons [3, 4]. Normally, monoamine oxidase enzyme (MAO type A) located in the intestinal wall breaks down dietary tyramine in the gut before it can be absorbed into the circulation. Patients taking MAO inhibitors are advised to take very careful precautions not to eat foods with high tyramine content, such as aged cheese, red wine, and fava beans, because the large amount of tyramine absorbed in these patients stimulates the release of norepinephrine from nerve endings in blood vessels and the heart, causing a hypertensive crisis [5]. Norepinephrine release combined with MAO inhibition may result in autopotentiation of sympathomimetic effects [6]. Individuals taking MAOI were more sensitive to the pressor effects of tyramine than controls [7]. High levels of tyramine are found in aged cheese [8].

Our patient, who had no prior history of any cardiac problems, hypertension or drug overdose or abuse was
Fig. 4 Electrocardiography of the patient prior to discharge

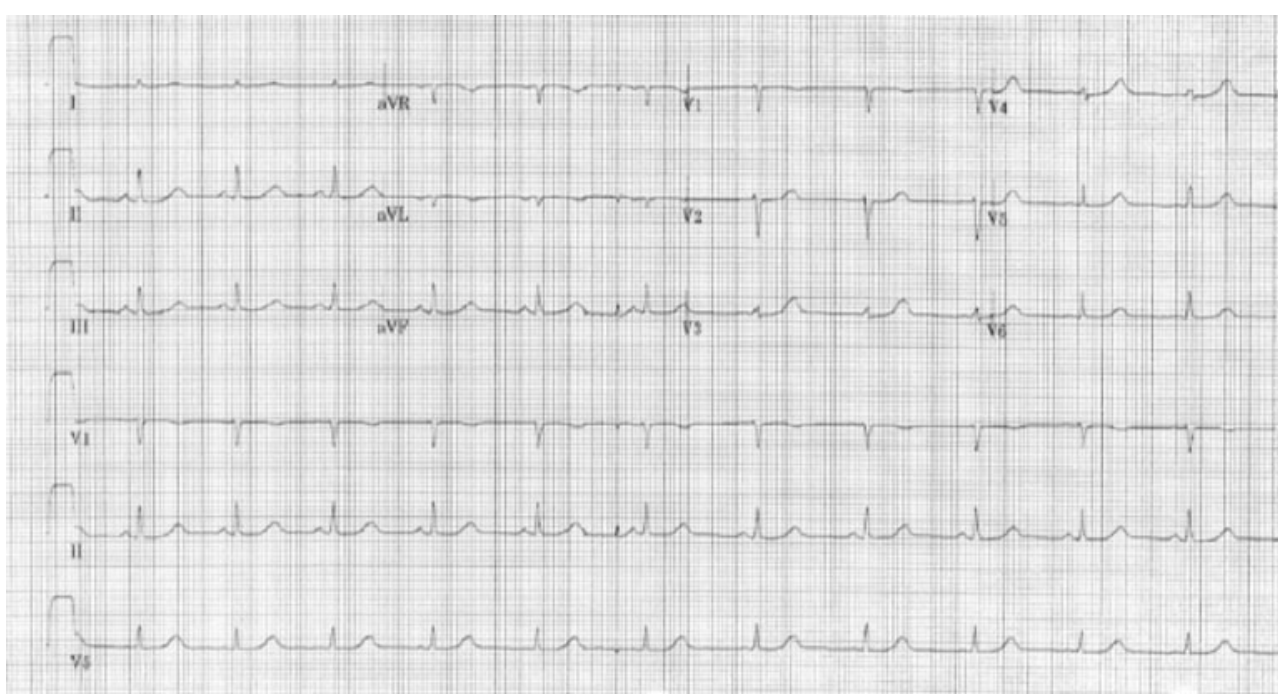


found to be symptomatic within $1.5 \mathrm{~h}$ after the ingestion of cheese. This is consistent with the early clinical manifestations with an onset of symptoms within minutes to hours, compared with the delayed onset of symptoms characteristic of acute MAOI overdose [9-12]. Tyramine-induced MAOI reactions have included headache, flushing, and diaphoresis as well as cerebral hemorrhage [13-15]. It might be expected that hypertensive crisis could lead to a myocardial infarction [5], but a review of the medical literature found no such cases reported.

The patient's initial blood pressure of $176 / 80 \mathrm{mmHg}$ is high. Her baseline blood pressure of $99 / 60 \mathrm{mmHg}$ represents a rise of nearly $80 \mathrm{~mm} \mathrm{Hg}$ in systolic and $20 \mathrm{~mm} \mathrm{Hg}$ in diastolic blood pressure. This is concerning as such a rise in blood pressure may induce a myocardial event in an otherwise healthy young female. In patients with MAOI hypertensive crisis who complain of chest tightness, it would be prudent to perform serial electrocardiograms and cardiac enzymes and manage the patient according to guidelines for unstable angina or non-ST elevation myocardial infarction until proven otherwise.

The patient was started on nitroprusside as it is a rapid, short-acting parenteral agent [16]. The hypotension that occurred about $8 \mathrm{~h}$ after her admission might have been due to excessive dosing of nitroprusside, vasodilation from administered morphine, or possibly related to norepinephrine depletion in adrenergic neurons from monoamine oxidase inhibitor administration with tyramine ingestion [17]. Beta blockers were not used because of the theoretical concern for paradoxical worsening of hypertension as a result of unopposed alpha-adrenergic stimulation [18].

It was fortunate that the patient's hypotension was responsive to fluids alone. In the event that hypotension is unresponsive to fluids, the pressor of choice should be a direct-acting alpha-adrenergic agonist such as norepinephrine, which circulates extracellularly and binds directly to post-synaptic receptors and does not require the release of intracellular amines, whose stores and kinetics may otherwise have been altered by MAOIs [2].

Although MAOIs are currently rarely used in clinical practice, having been replaced by other antidepressants, there are still a few patients who take these drugs and are at risk for hypertensive reactions after use of pseudoephedrine or ingestion of tyramine-containing foods.

Reversible inhibitors of monoamine oxidase type A (RIMAs), a subset of MAO inhibitors that inhibit monoamine oxidase temporarily, are reversible, selective, and have a short duration of action; a strict diet is not required during RIMA therapy. They may be a good alternative to the conventional MAOIs as hypertensive crisis is rare [19].

\section{Conclusion}

Myocardial infarction should be considered in the spectrum of potential complications when a patient on MAOI ingests tyramine-containing foods.

Funding There is no funding for this project.

Conflicts of interest There are no known conflicts of interest.

\section{References}

1. Linden CH, Rumach BH, Strehilke C (1984) Monoamine oxidase inhibitor overdose. Ann Emerg Med 13:1137-1144

2. Smookler S, Bermudez AJ (1982) Hypertensive crisis resulting from an MAO inhibitor and an over-the-counter appetite suppressant. Annals of Emerg Med 11(9):482-484

3. Lee WC, Shin YH, Shideman FE (1961) Cardiac activities of several monoamine oxidase inhibitors. J Pharmacol Exp Ther 133:180-185

4. D'Mello A (1968) Interaction between phenylpropanolamine and monoamine oxidase inhibitors. J Pharm Pharmacol 21:577-580

5. Kokan L, Benowitz NL (2007) Monoamine oxidase inhibitors. In KR Olson (Ed.) Poisoning and drug overdose, 5th edn. (pp. 269272). International edition: McGraw-Hill Lange

6. Marley E, Blackwell B (1970) Interactions of monoamine oxidase inhibitors, amines, and foodstuffs. Adv Pharm Chemother 7:185-239

7. Horowitz D, Lovenberg W, Engelman K (1964) Monoamineoxidase inhibitors, tyramine and cheese. JAMA 188:118

8. Blackwell B (1963) Hypertensive crisis due to monoamine oxidase inhibitors. Lancet $2: 849$

9. Kokan L (2002) Monoamine oxidase inhibitors. In LR Goldfrank, NE Flomenbaum, NA Lewin, MA Howland, RS Hoffmann, LS Nelson (Eds.) Goldfrank's toxicologic emergencies, 7th edn (pp 890). Medical Publishing Division, International: McGraw-Hill

10. Keck PE, Vuckovic A, Pope HG, Nierenberg AA, Gribble GW, White K (1989) Acute cardiovascular response to monoamine oxidase inhibitors: a prospective assessment. J Clin Psychopharmacol 9 (3):203-206

11. Linet LS (1986) Mysterious MAOI hypertensive episodes. J Clin Psychiatry 47:563-565

12. Fallon B, Fotoe B, Walsh BT, Roose SP (1988) Spontaneous hypertensive episodes with MAOI. J Clin Psychiatry 49:162-165

13. Golwyn DH, Sevlie CP (1993) Monoamine oxidase inhibitor hypertensive crisis headache and orthostatic hypotension. J Clin Psychopharmacol 13(1):77-78

14. De Villiers JC (1966) Intracranial haemorrhage in patients treated with monoamineoxidase inhibitors. Br J Psychiatry 112(483):109-118

15. Bethune HC, Burrell RH, Culpan H, Ogg GJ (1964) Vascular crisis associated with monoamine-oxidase inhibitors. Am J Psychiatry 121:245-248

16. Kearney TE (2007) Nitroprusside. In KR Olson (Ed.) Poisoning and drug overdose, 5th edn. (pp. 485-487). International edition: McGraw-Hill Lange

17. Gessa GL, Cuenca E, Costa E (1963) On the mechanism of hypotensive effects of MAO inhibitors. Ann N Y Acad Sci 8 (107):935-944

18. Frieden J (1967) Propanolol as an antiarrythmic agent. Am Heart J $74: 283-285$

19. Lotufo-Neto F, Trivedi, Thase ME (1999) Meta-analysis of the reversible inhibitors of monoamine oxidase type A moclobemide and brofaromine for the treatment of depression. Neuropsychopharmacology 20(3):226-247 